\title{
A comparison of posterior lumbar interbody fusion and transforaminal lumbar interbody fusion: a literature review and meta-analysis
}

\author{
Qunhu Zhang ${ }^{\dagger}$, Zhen Yuan ${ }^{\dagger}$, Min Zhou, Huan Liu, Yong Xu and Yongxin Ren ${ }^{*}$
}

\begin{abstract}
Background: We compared the perioperative results and complications associated with PLIF and TLIF, and collected evidence for choosing the better fusion method.

Methods: A literature survey of the MEDLINE and EMBASE databases identified 7 comparative observational studies that met our inclusion criteria. Checklists by Cowley were used to evaluate the risk of bias of the included studies. A database including patient demographic information, perioperative results, and complications was established. The summary odds ratio and weighed mean difference with 95\% confidence interval were calculated with a random-effects model.

Results: We found that PLIF had a higher complication rate $(P<0.00001)$, and TLIF reduced the rate of durotomy $(P=0.01)$. No statistical difference was found between the two groups with regard to clinical satisfaction $(P=0.54)$, blood loss $(P=0.14)$, vertebral root injury $(P=0.08)$, graft malposition $(P=0.06)$, infection $(P=0.36)$, or rate of radiographic fusion ( $P=0.27)$. The evidence indicated that PLIF required longer operative time $(P=0.03)$.

Conclusions: The evidence indicated that TLIF could reduce the complication rate and durotomy. Neither TLIP nor PLIF was found superior in terms of clinical satisfaction or radiographic fusion rate. PLIF might result in longer time in surgery.
\end{abstract}

Keywords: Posterior lumbar interbody fusion, Transforaminal lumbar interbody fusion, Meta-analysis, Lumbar fusion

\section{Background}

The optimal treatment for degenerative lumbar diseases remains controversial $[1,2]$. The currently recommended surgical procedures are the anterior lumbar interbody fusion, the posterior lumbar interbody fusion (PLIF), and the transforaminal lumbar interbody fusion (TLIF) [3-7]. The PLIF and TLIF are the more commonly implemented [8-12].

PLIF was first described by Cloward in 1940 and became commonly used after modifications were proposed by Lin $[13,14]$. PLIF can only be performed through the posterior approach, and it enables a stable three-column fixation with $360^{\circ}$ fusion and anterior support [15-17]. In 1982, Harms and Rolinger first described the TLIF technique for creating a circumferential fusion via a single posterolateral approach [18]. As reported by Audat

\footnotetext{
* Correspondence: renyongxin@aliyun.com

${ }^{\dagger}$ Equal contributors

Department of Orthopedics, The First Affiliated Hospital of Nanjing Medical University, 300 Guangzhou Road, Nanjing, 210029, Jiangsu, People's Republic of China
}

\section{Ciomed Central}

(C) 2014 Zhang et al.; licensee BioMed Central Ltd. This is an Open Access article distributed under the terms of the Creative Commons Attribution License (http://creativecommons.org/licenses/by/4.0), which permits unrestricted use, distribution, and reproduction in any medium, provided the original work is properly credited. The Creative Commons Public Domain Dedication waiver (http://creativecommons.org/publicdomain/zero/1.0/) applies to the data made available in this article unless otherwise stated. et al., in 1998 Harms and Rolinger reported the treatment outcomes of 191 patients who received TLIF between 1993 and $1996[19,20]$. This procedure involves the placement of pedicle screws and an interbody spacer via a single posterolateral route.

Many studies have compared methods for lumbar interbody fusion with regard to clinical results and fusion rates [20-22]. However, the inconsistent results of these studies do not provide sufficient evidence to determine which is the optimal fusion technique. The present study is a meta-analysis, conducted to provide cumulative effect estimates of clinical outcomes and to determine which surgical technique is more beneficial.

\section{Methods}

Search strategy and inclusion criteria

A survey was conducted of literature published until June 2013 using the MEDLINE and EMBASE databases. All fields were screened using the key terms "posterior lumbar interbody fusion" or "PLIF" combined with "transforaminal 
lumbar interbody fusion" or "TLIF". Pertinent articles in reference lists were also inspected.

Studies were included in this meta-analysis if they met the following criteria: 1) the study design was comparative (i.e., PLIF compared to TLIF); 2) the study population consisted of adult patients suffering from degenerative lumbar diseases (disc herniation, spinal stenosis, or spondylolisthesis); 3) the study reported at least one desirable outcome regarding perioperative results (e.g., operative time, blood loss), complications, pain or disability improvement, or fusion rate; 4) the patients were followed up for at least 6 months after surgery; and 5) each group comprised at least 10 patients. Excluded from the present meta-analysis were case reports, reviews, biomechanical and cadaveric studies, and repeated studies.

\section{Data extraction and quality assessment}

The following information was extracted from each publication: 1) the first author's last name, study year, country and study design; 2) basic study characteristics including the number of enrolled patients, age, and gender proportion; 3) perioperative results such as operative duration, blood loss, and hospitalization; 4) complication types and rates; and 5) fusion rate. Both intraoperative and postoperative complications were extracted. Complication types were defined as in previous published reviews [18].

The quality of the included studies was evaluated using the Cowley criteria. A Cowley score $\geq 9$ out of a possible 17 was considered high methodological quality $[23,24]$.

\section{Meta-analysis}

The analysis was conducted with the statistical software Review Manager Version 5.2 (Cochrane Collaboration) using a random effects model. Continuous outcomes were calculated by the weighted mean difference (WMD) and 95\% confidence interval (CI). Dichotomous variables were summarized using the odds ratio (OR) and 95\% CI. Heterogeneity was evaluated using I2 statistics. I2 values of $<25 \%$, $25-50 \%, 50-75 \%$, and $>75 \%$ were considered to indicate no, low, moderate, and high heterogeneity, respectively. Funnel plots were employed to assess the possibility of publication bias.

\section{Results}

\section{Literature surve}

Seven non-randomized comparative studies were identified (Figure 1). The basic strategy yielded 192 records. Fifty-four full texts were screened by titles and abstracts. Nineteen case reports, reviews, and biomechanical and cadaveric studies were excluded. No eligible studies were found in the search of the references of the retrieved articles. Finally, the outcomes of 647 patients were included in the meta-analysis.

\section{Study characteristics}

Four studies consisted of patients who had received a diagnosis of degenerative disc disease [19-22] and in four studies lumbar instability and spondylolisthesis had been diagnosed (Table 1) $[19,22,25,26]$. One study comprised patients with recurrent lumbar disc protrusion [27].

The included articles were scored in accordance with the Cowley criteria (Table 1). The Cowley scores of the 7 comparative studies ranged from 10 to 14 out of a possible 17. Therefore, the included studies were considered of high methodological quality.

\section{Meta-analysis results Complications}

All of the 7 studies reported complications associated with surgery [19-22,25-27]. Durotomy, root injury, infection, cerebrospinal fluid leakage, and implant migration were observed [28-30]. The overall complication rate was significantly higher in the PLIF group than the TLIF (OR 4.05, 95\% CI: 2.36 to 6.94, $\mathrm{P}<0.00001$ ). There was no evidence for significant heterogeneity $\left(\mathrm{I}^{2}=0 \%, \mathrm{P}=0.63\right.$; Figure 2).

Durotomy was reported in 5 studies [21,22,25-27], and the overall difference in durotomy rates was statistically significant (OR 3.03, 95\% CI: 1.24 to $7.40, \mathrm{P}=0.01$ ). Statistical heterogeneity was not detected among the studies with regard to durotomy $\left(\mathrm{I}^{2}=0 \%, \mathrm{P}=0.85\right.$; Figure 2$)$.

The rates of root injury (OR 2.53, 95\% CI: 0.89 to 7.18 , $\mathrm{P}=0.08$ ), graft (pedicle screw, cage, and bone graft) malposition (OR $3.68,95 \% \mathrm{CI}: 0.94$ to $14.50, \mathrm{P}=0.06$ ) and infection (OR 1.70, 95\% CI: 0.55 to $5.22, \mathrm{P}=0.36$ ) were similar between the TLIF and PLIF groups. There was no evidence of significant heterogeneity with regard to complications $\left(\mathrm{I}^{2}=0 \%, \mathrm{P}>0.1\right.$; Figure 2$)$. One study reported cerebrospinal fluid leakage but the difference was not statistically significant between the two groups [21].

\section{Clinical satisfaction}

Five studies reported evaluations of satisfaction made by patients, or clinical satisfaction was assessed based on the Oswestry disability index (ODI) or Japanese Orthopedic Association (JOA) scores. No statistical difference was found between the two groups (OR 0.81, 95\% CI: 0.42 to $1.57, \mathrm{P}=0.54)$. There was no evidence for significant heterogeneity $\left(\mathrm{I}^{2}=0 \%, \mathrm{P}=0.99\right.$; Figure 3$)$. The evidence from one-year follow-up studies showed that there was no statistically significant difference between the two procedures (OR 0.82, 95\% CI: 0.28 to $2.40, \mathrm{P}=0.72$ ) $[21,22,26]$. The follow-up period of two studies was two years [25,27], and no statistical difference was found (OR 0.81, 95\% CI: 0.35 


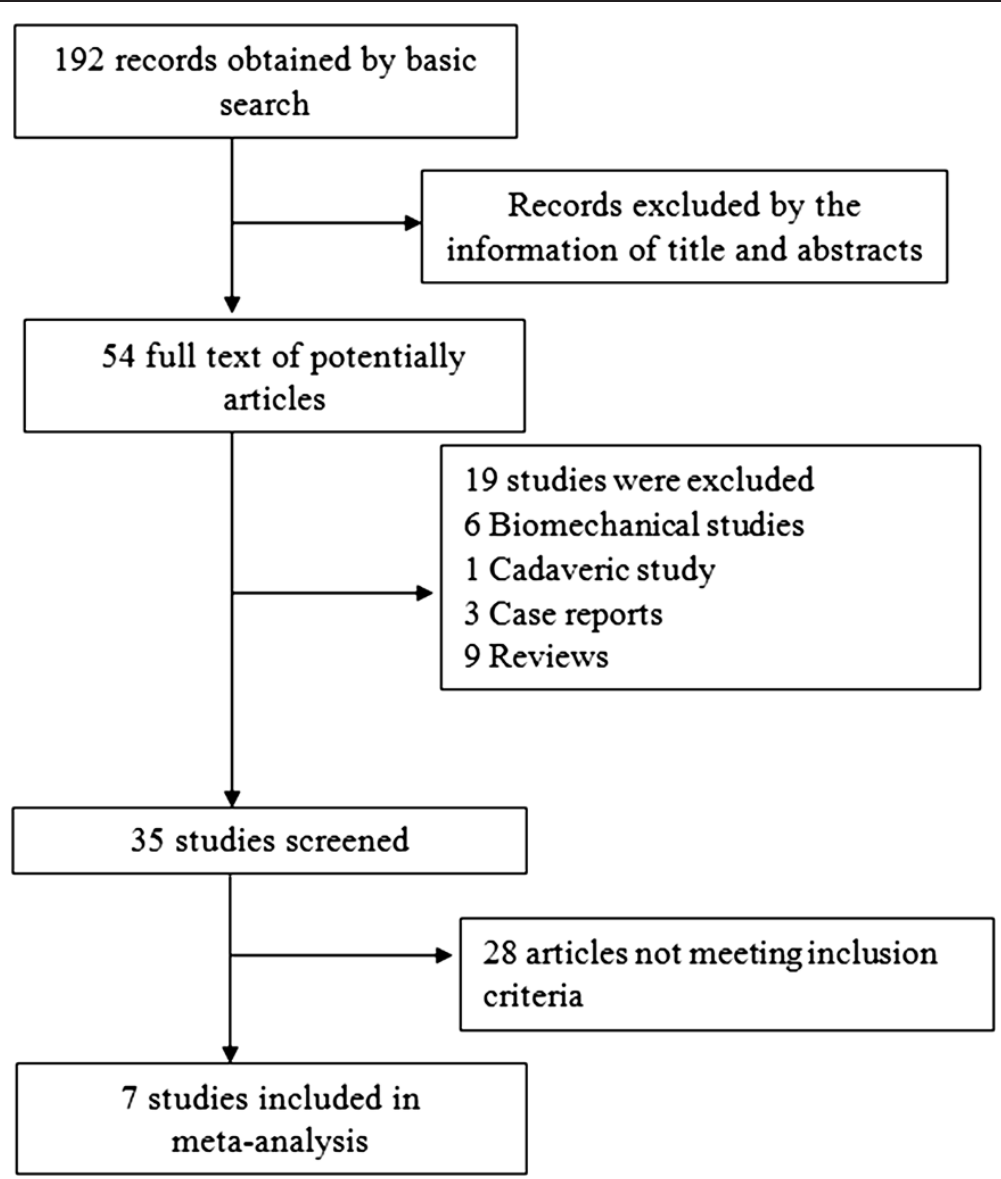

Figure 1 Flow diagram of the selection process.

to $1.86, \mathrm{P}=0.61$ ). Subgroup analysis showed similar trends in the one-year and two-year follow-up periods.

\section{Fusion rate}

Data regarding fusion rates were available in four studies and none of them reported statistically significant differences [22,25-27]. Overall, the fusion rate was similar for both groups (OR 0.52, 95\% CI: 0.16 to $1.68, \mathrm{P}=0.27$ ). Chisquared tests indicated no statistical evidence of heterogeneity $\left(\mathrm{I}^{2}=0 \%, \mathrm{P}=0.63\right.$; Figure 3$)$.

\section{Operative time}

Operative time was recorded in four studies [19,22,26,27] and two studies reported statistically significant differences showing that PLIF requires more time [26,27]. Two of them provided the mean and $\mathrm{P}$ values $[19,22]$. Two studies reported adequate mean and standard deviation data [26,27]. The WMD for operative time was 29.85 minutes longer for the PLIF group than the TLIF group (95\% CI: 2.50 to 57.20), $\mathrm{P}=0.03)$. High heterogeneity existed among the studies $\left(\mathrm{I}^{2}=91 \%, \mathrm{P}=0.0009\right.$; Figure 4$)$.

Table 1 Characteristics and evaluation of included studies*

\begin{tabular}{llllllll}
\hline & Year & \multirow{2}{*}{$\begin{array}{l}\text { Country } \\
\text { of origin }\end{array}$} & & \multicolumn{3}{c}{ PLIF/TLIF } & Evaluation \\
\cline { 5 - 8 } & & Patients, $\mathbf{n}$ & Mean age, $\mathbf{y}$ & Male, $\%$ & Mean follow up, months \\
\hline Humphreys et al. [19] & 2001 & USA & $34 / 40$ & $40.00 / 41.00$ & $64.71 / 50.00$ & $13.0 / 13.0$ & 10 \\
Jae-Sung Park et al. [22] & 2005 & Korea & $99 / 29$ & $54.00 / 57.00$ & $43.43 / 34.48$ & $20.0 / 10.4$ & 12 \\
Yan et al. [25] & 2008 & China & $60 / 60$ & $63.60 / 64.50$ & $55.00 / 53.33$ & $23.0 / 23.0$ & 14 \\
Zhuo et al. [27] & 2009 & China & $22 / 18$ & $41.00 / 43.00$ & $63.64 / 72.22$ & $20.0 / 20.0$ & 13 \\
Mehta et al. [21] & 2011 & USA & $76 / 43$ & $48.56 / 48.12$ & $44.74 / 37.21$ & $24.0 / 24.0$ & 11 \\
Audat et al. [20] & 2012 & Jordan & $27 / 37$ & $50.60 / 45.80$ & $22.22 / 37.84$ & $36.0 / 36.0$ & 13 \\
Sakeb et al. [26] & 2013 & Bangladesh & $52 / 50$ & $46.73 / 49.04$ & $21.15 / 28.00$ & $9.0 / 9.0$ & 14 \\
\hline
\end{tabular}

*All studies were retrospective and comparative. 


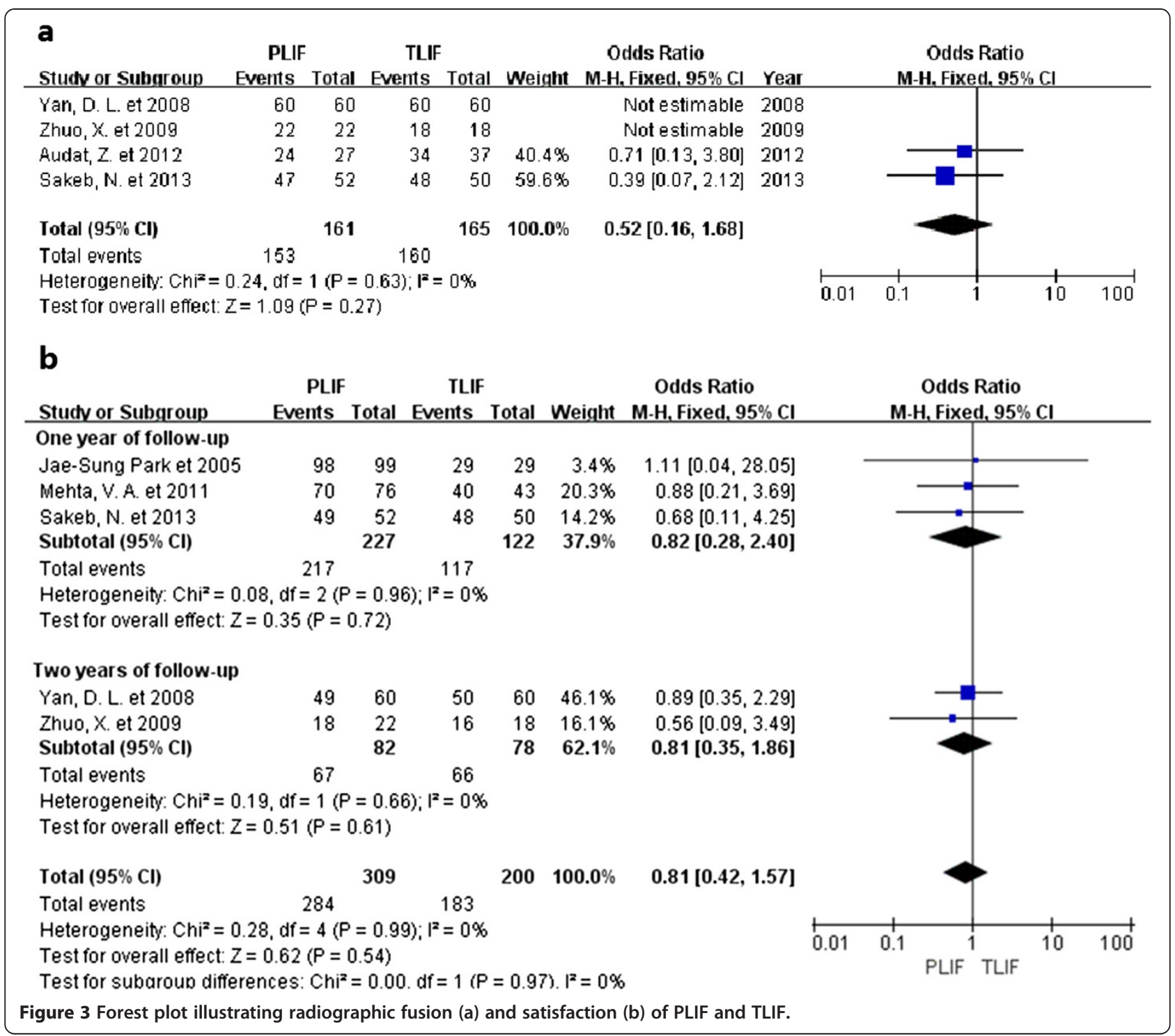

\section{Blood loss}

Details regarding intraoperative blood loss were available in four studies $[19,21,26,27]$. Three studies provided mean and standard deviation [21,26,27]; one study reported mean and P-value. Two studies showed statistically significant differences [26,27]. Overall, the WMD was equivalent for both the PLIF and TLIF groups (WMD = 142.05, 95\% CI: -48.76 to $332.86, \mathrm{P}=0.14)$. There was obvious evidence for statistically significant heterogeneity $\left(\mathrm{I}^{2}=96 \%, \mathrm{P}<0.00001\right.$; Figure 4).

\section{Sensitivity analysis}

Sensitivity analysis was conducted by reanalyzing the data after sequential omission of individual studies. Pooled results did not yield any significant difference after omitting the data of any single study.

\section{Discussion}

The evidence of this updated meta-analysis indicated that PLIF results in a higher complication rate than does TLIF, based on 7 high methodological quality studies of epidemiological data. PLIF required longer operative time than TLIF, while high heterogeneity existed among the studies. No significant difference was found between the two procedures regarding blood loss, clinical satisfaction, or fusion rate.

PLIF was associated with a significantly higher complication rate. However, since the types of complications or their definitions were inconsistent among the studies, pooling the complication data might lead to bias. The main complication types included durotomy, root injury, graft (pedicle screw, cage, and bone graft) malposition, and infection [28-30]. Compared with TLIF, the incidence of durotomy was higher in PLIF. A trend in increased risk of root injury 


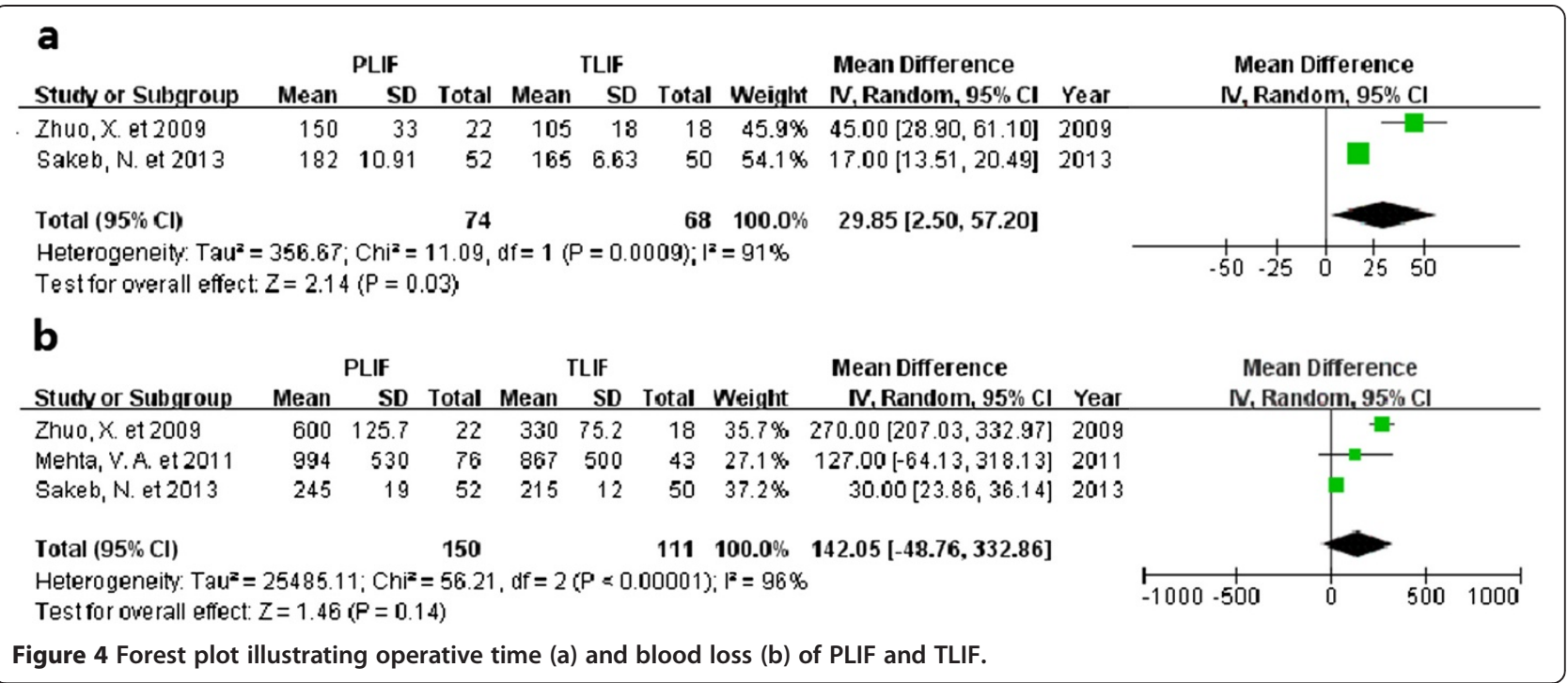

and graft malposition was also observed for PLIF, although the difference was not statistically significant. Because the approach in the TLIF technique is lateral to the vertebral foramen, there is less retraction of the dura or conus medullaris, and greater protection of the spinous processes that can affect postoperative spinal stability [31-36]. This leads to a lower incidence of durotomy and root injury in TLIF groups than in the PLIF. Our present meta-analysis supports this theoretical assumption, and may explain the lower incidence of graft malposition in TLIF. Because TLIF preserves the posterior compartment more effectively than PLIF does, transitional syndrome or screw fracture is less likely to occur.

The PLIF procedure required longer operative time. However, data among the studies were highly heterogeneous. A precise pooled mean difference could not be calculated because the number of studies providing the mean and standard deviation were insufficient. The broad dissection performed in PLIF might increase the operative time; but we still need more clinical data to support this conclusion. Over the past few years, modifications and refinements of surgical techniques have continually been made to achieve better outcomes [37-40]. Such modifications include minimization of neural retraction and avoidance of broad dissection of the paraspinal musculature. Efforts were also made to reduce complication rates and to develop minimally invasive spine surgery, which results in less blood loss $[34,35,41]$. Postoperative hospitalization was also reported $[21,22,26,27]$, and the P-value of these studies indicated no statistically significant difference.

For spinal surgeries, a better surgical technique should induce fewer complications as well as less blood loss. It is consistent with Takahashi et al. findings in 2011 [42]. TLIF is a satisfactory choice. Minimal invasive spine surgeries are expected to be adopted more and more widely in future clinical trials [43-47].

As with other systematic reviews, there were limitations to this study. Firstly, there were no high-quality randomized controlled trials included, and these are increasingly important in the evaluation of surgical treatments [48-50]. Furthermore, the sample size in some subgroup analyses was quite small. When continuous outcomes were pooled, statistical heterogeneity was evident; this might be explained by differences in study design and quality, patients' characteristics, and the diverse technical specifications. A further limitation is that clinical outcome data was sometimes incomplete. Finally, by its nature meta-analysis is just a statistical test that is subject to many methodological restrictions and is not able to control all relevant factors. Despite the above weaknesses, the present meta-analysis still has academic value.

\section{Conclusions}

TLIF was shown to result in a lower complication rate, and PLIF was associated with an increased risk of durotomy. In addition, low-quality evidence showed that the PLIF required longer operative time than the TLIF. Regarding blood loss and fusion rates, there was no significant difference between the two fusion procedures.

\section{Competing interests}

The authors declare that they have no competing interests.

\section{Authors' contributions}

QHZ contributed to the conception and design of the review; analysis and interpretation of data; and drafting and revising of the manuscript. ZY contributed to the conception and design of the review; analysis and interpretation of data; and drafting and revising of the manuscript. MZ, HL and $Y X$ contributed to collected background information, and helped to draft the manuscript. YXR conceived of the study, and participated in its 
design and coordination and helped to draft the manuscript. All authors read and approved the final manuscript.

\section{Authors' information}

Qunhu Zhang and Zhen Yuan: The first two authors should be regarded as joint First Authors.

\section{Acknowledgements}

No funding was received for this study.

Received: 7 June 2014 Accepted: 20 October 2014

Published: 5 November 2014

\section{References}

1. Gu G, Zhang H, Fan G, He S, Cai X, Shen X, Guan X, Zhou X: Comparison of minimally invasive versus open transforaminal lumbar interbody fusion in two-level degenerative lumbar disease. Int Orthop 2014, 38:817-824.

2. Ye YP, Xu H, Chen D: Comparison between posterior lumbar interbody fusion and posterolateral fusion with transpedicular screw fixation for isthmic spondylolithesis: a meta-analysis. Arch Orthop Trauma Surg 2013, 133:1649-1655.

3. Kim YJ, Bridwell KH, Lenke LG, Rhim S, Cheh G: Pseudarthrosis in long adult spinal deformity instrumentation and fusion to the sacrum: prevalence and risk factor analysis of 144 cases. Spine (Phila Pa 1976) 2006, 31:2329-2336.

4. Weistroffer JK, Perra JH, Lonstein JE, Schwender JD, Garvey TA, Transfeldt EE, Ogilvie JW, Denis F, Winter RB, Wroblewski JM: Complications in long fusions to the sacrum for adult scoliosis: minimum five-year analysis of fifty patients. Spine (Phila Pa 1976) 2008, 33:1478-1483

5. Jacobs WC, Vreeling A, De Kleuver M: Fusion for low-grade adult isthmic spondylolisthesis: a systematic review of the literature. Eur Spine J 2006, 15:391-402.

6. Starkweather A: Posterior lumbar interbody fusion: an old concept with new techniques. J Neurosci Nurs 2006, 38:13-20. 30.

7. Moskowitz A: Transforaminal lumbar interbody fusion. Orthop Clin North Am 2002, 33:359-366.

8. Gjessing $\mathrm{MH}$ : Osteoplastic anterior fusion of the lower lumbar spine in spondylolisthesis, localized spondylosis, and tuberculous spondylitis. Acta Orthop Scand 1951, 20:200-213.

9. Cloward RB: Spondylolisthesis: treatment by laminectomy and posterior interbody fusion. Clin Orthop Relat Res 1981, 154:74-82.

10. Schnee $\mathrm{CL}$, Freese A, Ansell LV: Outcome analysis for adults with spondylolisthesis treated with posterolateral fusion and transpedicular screw fixation. J Neurosurg 1997, 86:56-63.

11. Salehi SA, Tawk R, Ganju A, LaMarca F, Liu JC, Ondra SL: Transforaminal lumbar interbody fusion: surgical technique and results in 24 patients. Neurosurgery 2004, 54:368-374.

12. Kunze B, Drasseck T, Kluba T: Posterior and transforaminal lumbar interbody fusion (PLIF/TLIF) for the treatment of localised segment degeneration of lumbar spine. Z Orthop Unfall 2011, 149:312-316.

13. Cloward RB: The treatment of ruptured lumbar intervertebral discs by ventral fusion: indications, operative technique, after care. J Neurosurg 1953, 10:154-168.

14. Lin PM: A technical modification of Cloward's posterior lumbar interbody fusion. Neurosurgery 1977, 1:118-124.

15. Fraser RD: Interbody, posterior, and combined lumbar fusions. Spine 1995, 20:167-177.

16. Cunningham BW, Polly DW Jr: The use of interbody cage devices for spinal deformity: a biomechanical perspective. Clin Orthop Relat Res 2002, 394:73-83.

17. Madan S, Boeree NR: Outcome of posterior lumbar interbody fusion versus posterolateral fusion for spondylolytic spondylolisthesis. Spine (Phila Pa 1976) 2002, 27:1526-1542.

18. Harms J, Rolinger $\mathrm{H}$ : A one-stage procedure in operative treatment of spondylolisthesis: dorsal traction-reposition and anterior fusion. Z Orthop Ihre Grenzgeb 1982, 120:343-347.

19. Humphreys SC, Hodges SD, Patwardhan AG, Eck JC, Murphy RB, Covington $L A$ : Comparison of posterior and transforaminal approaches to lumbar interbody fusion. Spine 2001, 26:567-571.

20. Audat Z, Moutasem O, Yousef K, Mohammad B: Comparison of clinical and radiological results of posterolateral fusion, posterior lumbar interbody fusion and transforaminal lumbar interbody fusion techniques in the treatment of degenerative lumbar spine. Singapore Med J 2012, 53:183-187

21. Mehta VA, McGirt MJ, Garcés Ambrossi GL, Parker SL, Sciubba DM, Bydon A, Wolinsky JP, Gokaslan ZL, Witham TF: Trans-foraminal versus posterior lumbar interbody fusion: comparison of surgical morbidity. Neurol Res 2011, 331:38-42.

22. Park JS, Kim YB, Hong HJ, Hwang SN: Comparison between posterior and transforaminal approaches for lumbar interbody fusion. J Korean Neurosurg Soc 2005, 37:340-344.

23. Cowley DE: Prostheses for primary total hip replacement. A critical appraisal of the literature. Int J Technol Assess Health Care 1995, 11:770-778.

24. Liu X, Wang Y, Qiu G, Weng X, Yu B: A systematic review with metaanalysis of posterior interbody fusion versus posterolateral fusion in lumbar spondylolisthesis. Eur Spine J 2013, 23:43-56.

25. Yan DL, Li J, Gao LB, Soo CL: Comparative study on two different methods of lumbar interbody fusion with pedicle screw fixation for the treatment of spondylolisthesis. Zhonghua Wai Ke Za Zhi 2008, 467:497-500.

26. Sakeb N, Ahsan K: Comparison of the early results of transforaminal lumbar interbody fusion and posterior lumbar interbody fusion in symptomatic lumbar instability. Indian J Orthop 2013, 47:255-263.

27. Zhuo X, Hu J, Li B, Sun H, Chen Y, Hu Z: Comparative study of treating recurrent lumbar disc protrusion by three different surgical procedures. Zhongguo Xiu Fu Chong Jian Wai Ke Za Zhi 2009, 23:1422-1426.

28. Chrastil J, Patel AA: Complications associated with posterior and transforaminal lumbar interbody fusion. J Am Acad Orthop Surg 2012, 5:283-291.

29. Wu RH, Fraser JF, Hartl R: Minimal access versus open transforaminal lumbar interbody fusion: meta-analysis of fusion rates. Spine 2010, 35:2273-2281.

30. Zhao FD, Yang W, Shan Z, Wang J, Chen HX, Hong ZH, Qian Y, He DW, Fan SW: Cage migration after transforaminal lumbar interbody fusion and factors related to it. Orthop Surg 2012, 4:227-232.

31. Rosenberg WS, Mummaneni PV: Transforaminal lumbar interbody fusion: technique, complications, and early results. Neurosurgery 2001, 48:569-574.

32. Chrastil J, Patel AA: Complications associated with posterior and transforaminal lumbar interbody fusion. J Am Acad Orthop Surg 2012, 20:283-291.

33. Harris BM, Hilibrand AS, Savas PE: Transforaminal lumbar interbody fusion: The effect of various instrumentation techniques on the flexibility of the lumbar spine. Spine 2004, 29:65-70.

34. Mura PP, Costaglioli M, Piredda M, Caboni S, Casula S: TLIF for symptomatic disc degeneration: a retrospective study of 100 patients. Eur Spine J 2011, 1:S57-60.

35. Jiang JY, Ma X, Lü FZ, Wang HL, Chen WJ, Ma XS, Xia XL: The anatomic study and clinical significance of the modified transforaminal lumbar interbody fusion. Zhonghua Wai Ke Za Zhi 2009, 47:1100-1103.

36. DiPaola CP, Molinari RW: Posterior lumbar interbody fusion. J Am Acad Orthop Surg 2008, 16:130-139.

37. Lowe TG, Tahernia AD, O'Brien MF: Unilateral transforaminal posterior lumbar interbody fusion(TLIF): indications, technique, and 2-year results. J Spinal Disord Tech 2002, 15:31-38.

38. Mukai Y, Takenaka S, Hosono N, Miwa T, Fuji T: Intramuscular pressure of the multifidus muscle and low-back pain after posterior lumbar interbody fusion: comparison of mini-open and conventional approaches. J Neurosurg Spine 2013, 19:651-657.

39. Lian XF, Hou TS, Xu JG, Zeng BF, Zhao J, Liu XK, Zhao C, Li H: Posterior lumbar interbody fusion for aged patients with degenerative spondylolisthesis: is intentional surgical reduction essential? Spine J 2013, 13:1183-1189.

40. Xu H, Tang H, Guan X, Jiang F, Xu N, Ju W, Zhu X, Zhang X, Zhang Q, Li M: Biomechanical comparison of posterior lumbar interbody fusion and transforaminal lumbar interbody fusion by finite element analysis. Neurosurgery 2013, 72:21-26.

41. Tian NF, Wu YS, Zhang XL, Xu HZ, Chi YL, Mao FM: Minimally invasive versus open transforaminal lumbar interbody fusion: a meta-analysis based on the current evidence. Eur Spine J 2013, 22:1741-1749.

42. Takahashi T, Hanakita J, Minami M, Kitahama Y, Kuraishi K, Watanabe M, Takeshima Y, Uesaka T: Clinical outcomes and adverse events following transforaminal interbody fusion for lumbar degenerative spondylolisthesis in elderly patients. Neurol Med Chir 2011, 51:829-835. 
43. Spoor $A B$, Öner FC: Minimally invasive spine surgery in chronic low back pain patients. J Neurosurg Sci 2013, 57:203-218.

44. Kimball J, Yew A, Getachew R, Lu DC: Minimally invasive tubular surgery for transforaminal lumbar interbody fusion. Neurosurg Focus 2013, 35:Video 19

45. Su K, Guo Y, Zhang Z, Jin D: Research progress in comparison of minimally invasive versus open transforaminal lumbar interbody fusion Zhongguo Xiu Fu Chong Jian Wai Ke Za Zhi 2013, 27:1386-1389.

46. Singh K, Nandyala SV, Marquez-Lara A, Fineberg SJ, Oglesby M, Pelton MA, Andersson GB, Isayeva D, Jegier BJ, Phillips FM: A perioperative cost analysis comparing single-level minimally invasive and open transforaminal lumbar interbody fusion. Spine J 2013, S1529-9430:01723-3.

47. Seng C, Siddiqui MA, Wong KP, Zhang K, Yeo W, Tan SB, Yue WM: Five-year outcomes of minimally invasive versus open transforaminal lumbar interbody fusion: a matched-pair comparison study. Spine J 2013, 38:2049-2055

48. Balshem $H$, Helfand M, Schünemann HJ, Oxman AD, Kunz R, Brozek J, Vist GE, Falck-Ytter Y, Meerpohl J, Norris S, Guyatt GH: GRADE guidelines: 3. Rating the quality of evidence. J Clin Epidemiol 2011, 64:401-406.

49. Stroup DF, Berlin JA, Morton SC, Olkin I, Williamson GD, Rennie D, Moher D, Becker BJ, Sipe TA, Thacker SB: Meta-analysis of observational studies in epidemiology: a proposal for reporting. Meta-analysis of observational studies in epidemiology (MOOSE) group. JAMA 2000, 283:2008-2012.

50. Vlaanderen J, Vermeulen R, Heederik D, Kromhout H: Guidelines to evaluate human observational studies for quantitative risk assessment. Environ Health Perspect 2008, 116:1700-1705

doi:10.1186/1471-2474-15-367

Cite this article as: Zhang et al: A comparison of posterior lumbar interbody fusion and transforaminal lumbar interbody fusion: a literature review and meta-analysis. BMC Musculoskeletal Disorders 2014 15:367.

\section{Submit your next manuscript to BioMed Central and take full advantage of:}

- Convenient online submission

- Thorough peer review

- No space constraints or color figure charges

- Immediate publication on acceptance

- Inclusion in PubMed, CAS, Scopus and Google Scholar

- Research which is freely available for redistribution 